\title{
Characterization of the seed oils from kiwi (Actinidia chinensis), passion fruit (Passiflora edulis) and guava (Psidium guajava)
}

\author{
Georges PIOMBO ${ }^{1}$ \\ Nathalie BAROUH ${ }^{1}$ \\ Bruno BAREA ${ }^{1}$ \\ Renaud BOULANGER ${ }^{2}$ \\ Pierre BRAT ${ }^{3}$ \\ Michel PINA ${ }^{1}$ \\ Pierre VILLENEUVE ${ }^{1}$ \\ ${ }^{1}$ UMR IATE, Laboratoire de lipotechnie, CIRAD, \\ TA 40/16, 73 rue Jean François Breton, \\ 34398 Montpellier cedex 5 France \\ <piombo@cirad.fr> \\ 2 UR IMPACT, CIRAD Montpellier TA 40/16 \\ UPR- IMPACT, 73 rue Jean François Breton, \\ 34398 Montpellier Cedex 5, France \\ ${ }^{3}$ UR TROPIQUAL, CIRAD Montpellier TA 40/16, \\ 73, rue Jean François Breton, \\ 34398 Montpellier Cedex 5, France
}

\begin{abstract}
Oils extracted from three exotic fruits, guava, kiwi and passion fruit were analyzed to evaluate the possible commercial interest for these waste materials from fruit juices industry. Results showed interesting fatty acids compositions with high amounts of essential fatty acids such as $62.3 \%$ alpha linolenic acid for kiwi seed oil, and respectively $73.4 \%$ and $77.0 \%$ for omega 6 linoleic acid in passion fruit and guava seed oils. Fatty acids regiodistribution, sterols and tocopherols contents were also analyzed to try to establish the potential nutritional interest of such oils.
\end{abstract}

Key words: Kiwi, passion fruit, guava, fatty acid composition, regiodistribution, phytosterols, tocopherols

\section{Introduction}

All fruits are generally regarded as having nutritional value due to their vitamins and carbohydrates content of the pulp, however very little is known regarding the lipid quantity and quality found in the respective seeds. Increasingly lipids and therefore the lipid fraction are seen as beneficial for health, provided they are of specific composition and subscribe to nutritional recommendations such as the proportion of saturated, mono unsaturated, poly-unsaturated fatty acids and the ratio omega-6/omega-3 [1, 2].

While lipid composition is important, the bio-availability of the essential fatty acids is often determined by their regio-distribution on the glycerol back bone. Current evidence appears to suggest that the bio-availability of essential fatty acids is enhanced when they occupy the sn2 position.

From these preliminary considerations, we have chosen to study the lipid composition of seeds derived from three fruits: Kiwi (actinidia chinensis, passion fruit (edulis passiflora) and guava (psidium guajava). All three are marketed as either fresh or processed products and are valued for their ascorbic acid contents. As passion fruit, kiwi and guava contain on average $30 \mathrm{mg} / 100 \mathrm{~g}$, $60 \mathrm{mg} / 100 \mathrm{~g}$ and $250 \mathrm{mg} / 100 \mathrm{~g}$ respectively. In the case of kiwi and guava, this content can reach 300 and even $900 \mathrm{mg} / 100 \mathrm{~g}$ in certain varieties and according to the stage of maturity [3, 4].

These fruits are processed into a range of products i.e. juices, sorbets. However a considerable amount of the annual yield does not meet the prescribed criteria both for the fresh and processed markets thus leading to potential waste. In the case of kiwi this can account for $10-15 \%$ of the harvest. Attempts have been made to use these fruits in processing, but with little success, for example kiwi juices from smaller fruits do not offer the same, organoleptic quality and colour and cannot be stabilised. In this context the extraction of the oil from the seeds may provide an opportunity for adding value to a waste product. Therefore this article reports the characterisation and nutritional quality of the oils from these fruits.

\section{Materials and methods}

Material. Kiwis (Actinidia chinensis), Hayworth variety, were provided by the Barniol Company (Perpignan, France). The guavas (Psidium guajava), Beaumont variety came from Martinique (River Crack, France) and the passion fruits (Passiflora edulis), Pourpre variety of Kenya were provided by CIRAD Dept. FLHOR (Montpellier, France). 


\section{Oil Extraction}

The extraction of the seeds of kiwi was carried out after manual peeling of the kiwis and pressing using an Auriol press. The extract was subjected to simultaneous milling and sieving through a $6 \mathrm{~mm}$ mesh. The seeds are separated from the mixture by decanting in water. The seeds of guavas and passion fruits were obtained by manual extraction. Prior to extraction the seeds were ground using a grinder supplied by Retsch (Germany). We used an accelerated solvent extraction (ASE) system to extract oil witch petroleum ether (purchased from VWR international SAS France). This method is performed to optimize parameters such as temperature, pressure, extraction time). It replaces soxlhet extractor in several cases. Thanks to this method you can extract with higher temperature than the solvent extraction boiling point. This system is also interesting because it is shorter, it needs less solvent and the results obtained are comparable to those of the reference method $[5,6])$. The oil was extracted from a $4 \mathrm{~g}$ sample using a semiautomatic ASE200 (Accelerated Solvent Extraction, Dionex, USA) according to the following conditions: temperature $80^{\circ} \mathrm{C}, 7 \mathrm{~min}$ static time, 5 min dynamic time and a total rinsing volume of $11 \mathrm{ml}$. The cycle was repeated 5 times. This program ensures complete extraction of the neutral lipids from the sample at $80^{\circ} \mathrm{C}$ under a pressure of 100 bars for $60 \mathrm{~min}$. The extract was collected in an inactinic glass bottle. The solvent was driven off at $45^{\circ} \mathrm{C}$ using a rotary evaporator. The last solvent traces were removed by drying under nitrogen. The content of oil was determined by gravimetry.

\section{Transformation into fatty acids methyl esters (FAME) and GC analysis for Fatty acids composition}

In $25 \mathrm{~mL}$ round bottom flask, oil samples (10 mg) were added to $3 \mathrm{~mL}$ sodium methylate solution with phenolphtalein. Reaction medium was refluxed for $10 \mathrm{~min} .3 \mathrm{~mL}$ chlorhydric methanol were added to phenolphtalein discoloration and the mixture was refluxed again for $10 \mathrm{~min}$ and then cooled to ambient temperature. $8 \mathrm{~mL}$ hexane and $10 \mathrm{~mL}$ water were added and the organic phase was recovered, dried over anhydrous sodium sulfate and filtered for subsequent GC analysis: Agilent 6890 (Bios Analytique, France) series using a Innowax capillary column (SGE, Courtaboeuf, France) with the following characteristics: length, $30 \mathrm{~m}$; internal diameter, $0.32 \mathrm{~mm}$, film thickness $0.25 \mu \mathrm{m}$, Fatty acid methyl esters were directly injected into the GC. Carrier gas: Helium debit $1.0 \mathrm{~mL} / \mathrm{min}$, splitting ratio: $1 / 80$. Injector temp: $250^{\circ} \mathrm{C}$, FID Detector temp: $275^{\circ} \mathrm{C}$. oven was heated from $185^{\circ} \mathrm{C}$ to $225^{\circ} \mathrm{C}$ at $5{ }^{\circ} \mathrm{C} / \mathrm{min}$ and held at $225^{\circ} \mathrm{C}$ for $20 \mathrm{~min}$. Quantitative data were given by a D-2500 integrator (Merck, Darmstadt, Germany). Peak area percentages obtained with the integrator were divided by molecular weight of individual FAME (standards were purchased from Sigma-Aldrich, France) to yield mole percents of fatty acids. Two GC analyses of products from four experiments were made.

\section{Regiodistribution analysis of triacylglycerols (TAG)}

The regiodistribution analysis of TAG was performed after degradation to partial acylglycerols with ethyl magnesium bromide [7]. The resulting mixture of partial acylglycerols was separated by preparative thin-layer chromatography. The plates were developed with a chloroform/ acetone/acetic acid solution (85:15:1 v/v/v). The $\alpha$-monoacylglycerols $(\alpha-M A G)$ band was visualized under ultraviolet light $(R f=0.26)$ and scrapped off. The $\alpha$-MAG were converted to fatty acid methyl esters and analyzed by $\mathrm{GLC}$ according to the procedure described above.

\section{Phytosterols analysis}

The determination of phytosterols was carried out in accordance with the corresponding AFNOR Method NF ISO 6799 [8]. Sterols were extracted from $500 \mathrm{mg}$ of lipid extract. The sample was saponified using $5 \mathrm{ml}$ alcoholic Potassium carbonate $(0.5 \mathrm{~N})$, under reflux for $15 \mathrm{~min}$. The unsaponifiable components were separated from the soaps on a alumina column and washed with diethyl ether. The solvent was evaporated off and the residue was taken up in $1 \mathrm{~mL}$ of chloroform. The separation of sterols from other unsaponifiable components was carried out by thinlayer chromatography. The plates were developed with a hexane/diethyl ether/acetic acid solution (80:20:1 v/v/v). The individual sterol species were resolved using an Agilent 6890 coupled to a mass spectrometer Agilent 5973N GC fitted with a SAC5 column (length: $30 \mathrm{~m}$, internal diameter: $0.25 \mathrm{~mm}$, film thickness $0.25 \mu \mathrm{m}$ ) that allowed the direct analysis of sterols without derivatisation. The injector was set to $260^{\circ} \mathrm{C}$ with a split ratio of $1 / 50$. The carrier gas was helium at a flow rate of $1.5 \mathrm{ml} / \mathrm{min}$ and the oven temperature isotherm at $285^{\circ} \mathrm{C}$. The Mass spectrometer was operated in the electron impact ionization mode, the source temperature was programmed from $230^{\circ} \mathrm{C}$, the energy of ionisation was 70 electrons volts and the parameters of acquisition of the spectra are 40 to 400 uma for the range of mass. Two GC analyses of products from three experiments were made.

\section{Tocopherols analysis}

Tocopherols are analysed by HPLC in accordance with the AFNOR Method ISO 9936 [9]. The HPLC consists of modules provided by Thermo-Finnigan (France): a quaternary pump (P1000XR), a sample passor (AS1000) and a valve of injection to 6 ways provided with a loop of $20 \mu \mathrm{L}$, a spectrofluorimetric detector (FL3000) and software for data processing (PC 1000). The standards were purchased from VWR international SAS France. The mobile phase consists of a mixture of hexane/ dioxane $(97: 3 \mathrm{v} / \mathrm{v})$, with a flow of $1 \mathrm{~mL} / \mathrm{min}$. The column was a silica hypersil of $5 \mu \mathrm{m}(0,4 \mathrm{~cm}$ by $25 \mathrm{~cm})$. The wavelength of excitation was fixed at $290 \mathrm{~nm}$ and that of emission was regulated to $330 \mathrm{~nm}$. Analysis were run in triplicate.

\section{Determination of free fatty acid content (FFA)}

FFA content was determined by titration with $\mathrm{NaOH} 0.1 \mathrm{~mol} / \mathrm{L}$ using phenolphtalein as an indicator AOCS [10]. The amount of FFAs was calculated as wt $\%$ oleic acid. Analyses were carried out in triplicate.

\section{Results and discussion}

\section{Oil Content and FFA content}

The extraction of oil was carried out with accelerated extraction apparatus system (ASE 200). Oil content was respectively 30.0, 18.6 and 12.6\% for kiwi, passion fruit, and guava. The free fatty acid content of the three oils extracted expressed as a percentage of oleic acid was lower than $1 \%$ (respectively of $0.44 \%, 0.60 \%$, and of $0.23 \%$ for kiwi, passion fruit and guava). This is quite acceptable for a non-refined oil since, according to the codex Alimentarius criteria of quality for a crude oil are a FFA content of maximum $2 \%$ [11].

\section{FA composition and regiodistribution}

The FA compositions are shown in table 1. Kiwi seed oil was found to have a high percentage of essential fatty acids, omega 6 linoleic acid C18:2 n-6 (16.1\%) and omega 3 linolenic acid C18:3 n-3 (62.3\%) for a total of polyunsaturated fatty acids of $78.4 \%$. To the best of our knowledge, this oil can be considered as one of the richest source of omega 3 linolenic acid with comparable amount as the one found in linseed oil [12] and considerably higher than the one found in rapeseed or soy oil. Saturated fatty acids (SFA) represented less than $10 \%$ of the total fatty acids with palmitic $\mathrm{C} 16: 0$ (5.4\%) and stearic acid C18:0 (2.7\%) being the 


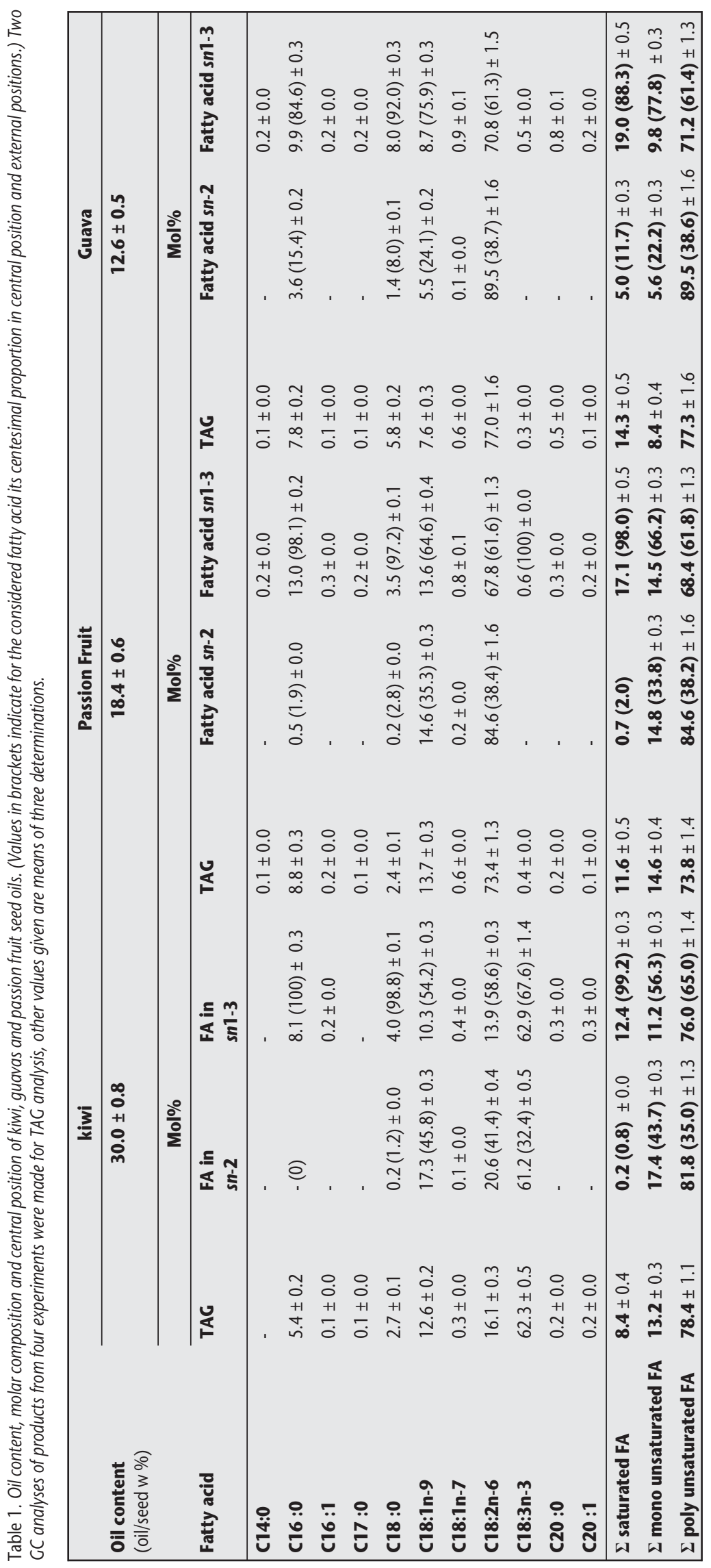


Table 2. Phytosterols content and proportions in kiwi, passion fruit and guava seed oils. (Values in brackets indicating the centesimal proportion of each phytosterols.) Tr = traces lower than $0.1 \mathrm{mg} / \mathrm{l00} \mathrm{g}$. $\mathrm{Nd}=$ Not detected. All values given are means of three determinations.

\begin{tabular}{|c|c|c|c|}
\hline & Kiwi & Passion Fruit & Guava \\
\hline Total amount (mg/100 g) & $269 \pm 8.0$ & $209 \pm 7.4$ & $329 \pm 9.3$ \\
\hline Campesterol & $7.2 \pm 0.8(2.1)$ & $28.2 \pm 1.9(13.5)$ & $9.9 \pm 0.9(3.0)$ \\
\hline Stigmasterol & $7.8 \pm 0.8(2.3)$ & $87.1 \pm 3.2(41.7)$ & $319.1 \pm 8.2(97.0)$ \\
\hline$\beta$-Sitosterol & $251.3 \pm 6.2(73.8)$ & $87.2 \pm 3.2(41.5)$ & $\mathrm{Tr}$ \\
\hline$\delta-5$ avenasterol & $2.7 \pm 0.4(0.8)$ & $6.9 \pm 0.9(3.3)$ & $\operatorname{Tr}$ \\
\hline$\delta$-7 Stigmasterol & $10.5 \pm 0.9(3.1)$ & $\mathrm{Nd}$ & $\mathrm{Nd}$ \\
\hline$\delta$-7 avénasterol & $14.7 \pm 1.4(4.3)$ & $\mathrm{Nd}$ & $\mathrm{Nd}$ \\
\hline
\end{tabular}

predominant ones in this family. Finally, monounsaturated acids accounted for $13.2 \%$ of total FA with a large majority of oleic acid C18:1 n-9 (12.6\%). This result and the others FA compositions of the tropical seed oils are according to the previous studies $[3,13,14]$.

Concerning the positional distribution of fatty acids within TAG, the regiospecific analysis of kiwi seed oil showed that $s n 2$ position was mainly occupied by unsaturated fatty acids with a large majority of C18:3n-3 (61.2\%) followed by C18:2 n-6 (20.6\%). On the contrary, saturated fatty acids were almost exclusively located on the two sn1 and sn3 external position. This results underlines the nutritional importance of such regiodistribution of essential fatty acids (C18:2 n-6 and C18:3n-3) since the localization of these latter at the central position of the TAG backbone assure their optimal bioavailabilty during absorption of kiwi seed oil [15]. Concerning passion fruit seed oil, a high ratio of linoleic acid C18:3 was observed (73.4\%) followed by oleic acid C18:1 (13.7\%) palmitic C16:0 (8.8\%) and stearic C18:0 (2.4\%) (table 2). Its regiodistribution study showed that saturated fatty acids are absent from central sn2 position while mono unsaturated are distributed equally among the three position. Finally, linoleic acid is preferentially located at the $s n 2$ position. The analysis of guava seed oil showed that this is also a linoleic oil (C18:2, $77.0 \%$ ). Its fatty acid composition is comparable to the one of passion fruit with lesser amounts of oleic acid C18:1 (7.6\%). Regiodistribution illustrates that linoleic occupies almost $90 \%$ of the sn2 position in TAG while SFA acid presents only $5 \%$.

Phytosterols analysis. The determination of phytosterols was carried out following the corresponding AFNOR Method [8] and CC-MS analysis. Results showed that guava seed oil was the richest in phytosterols with $329 \mathrm{mg} / 100 \mathrm{~g}$ whereas kiwi and passion fruit oils contain respectively 269 and $209 \mathrm{mg} / 100 \mathrm{~g}$ (table 2). In terms of different sterols proportion, stigmasterol was present in a very large majority in guava (97\%). Campesterol was detected at $9.9 \mathrm{mg} / 100 \mathrm{~g}$ accounting for $3.0 \%$ of total sterols. Others phytosterols were present in traces amounts or not detected. $\beta$-sitosterol is the more common phytosterol present in kiwi seed oil (73.8\%) while passion fruit oil contains equal amounts of $\beta$ sitosterol and stigmasterol. Finally, the presence of rare sterols such as $\delta-7$ stigmasterol $(10.5 \mathrm{mg} / 100 \mathrm{~g})$ and $\delta-7$ avenasterol $(14.7 \mathrm{mg} / 100 \mathrm{~g})$ is worth noting. Phytosterols, especially $\beta$-sitosterol, are been shown to exert protective effects against cardiovascular diseases as well as many types of cancer, several authors suggest. $\beta$-sitosterol can protect against oxidative stress through modulation of antioxydant enzymes $[16,17]$. These molecules could be used against ageing skin cells.

\section{Tocopherols analysis}

Guava seed oil was found to be the richest in tocopherols with 665 ppm in the crude oil (table 3). Passion fruit and kiwi showed lower quantities with respectively 465 and $312 \mathrm{ppm}$ In guava seed oil, $\gamma$-tocopherol was the predominant with $550 \mathrm{ppm}$ accounting for $82.7 \%$ of total tocopherols. A comparable repartition was observed with kiwi seed oil, which contains a majority of $\gamma$-tocopherol (84.3\%) while $\alpha$-tocopherol accounted for about $15.4 \%$. $\beta$-tocopherols and $\delta$-tocopherols were only present in traces quantities in this oil. Finally, passion fruit oil contain both $\gamma$-tocopherols and $\delta$-tocopherols in comparable amounts (217 and 243 ppm respectively). The quantity and nature of tocopherols naturally present in such unsaturated oils is of crucial importance regarding their oxidative stability. Indeed, tocopherols are natural antioxidants and depending of their nature, they can differ in their antioxidant capacity. Indeed, $\gamma$-tocopherols and $\delta$-tocopherols are believed to be better antioxidant than $\alpha$-and $\beta$-tocopherols [18]. Therefore, one can expect passion fruit and guava seed oils to be better protected against oxidation than kiwi seed oil owing to their higher amounts of $\gamma$-and $\delta$-tocopherols.

\section{Conclusion}

In summary, the results of this study illustrate the nutritional potential of the oils derived from the seeds of kiwi, passion fruit and Guava. Such oils were shown to contain significant amounts of polyunsaturated essential fatty acids with excellent bioavailability due to their preferential localisation at the sn2 position of triacylglycerols backbone. Moreover, these oils contain also significant amounts of sterols and tocopherols which justify their use in nutritional and cosmetic industry. The valorization of these waste materials becomes an attractive alternative because of the promising commercial application for its seed oil in cosmetics.

Table 3. Tocopherols weight contents in kiwi, passion fruits and guava seed oils (Values in brackets indicate the centesimal proportion of each tocopherol). Tr $=$ traces lower than $0.1 \mathrm{mg} / 100 \mathrm{~g}$. All values given are means of three determinations.

\begin{tabular}{|lccc|}
\hline & Kiwi & Passion Fruit & \multicolumn{1}{c|}{ Guava } \\
\hline Total amount $(\mathbf{p p m})$ & $312 \pm 7.5$ & $465 \pm 8.4$ & $665 \pm 7.5$ \\
$\boldsymbol{\alpha}$-tocopherol & $49 \pm 0.6(15.4)$ & $5.0 \pm 0.5(1.1)$ & $107 \pm 1.9(16.1)$ \\
$\boldsymbol{\beta}$-tocopherol & $\operatorname{Tr}$ & $\operatorname{Tr}$ & $3.0 \pm 0.4(0.5)$ \\
$\boldsymbol{\gamma}$-tocopherol & $263 \pm 5.5(84.3)$ & $217 \pm 5.8(46.5)$ & $550 \pm 6.4(82.7)$ \\
$\boldsymbol{\delta}$-tocopherol & $\operatorname{Tr}$ & $243 \pm 5.5(52.4)$ & $5.0 \pm 0.4(0.7)$ \\
\hline
\end{tabular}




\section{REFERENCES}

1. DUO L, BODE O, DRUMMOND H, SINCLAIR AJ. Omega-3(n-3) fatty acids. In: Gunstone FD, ed. Lipids for functional foods and nutraceuticals. Dundee: The Oily press, 2003: 225-62.

2. SIMOPOULOS AP. The importance of the ratio of omega-6/omega-3 essential fatty acids. Biomedecine Pharmacotherapy 2002; 56: 365-79.

3. MARCELIN O, MOURGUES ], TALMANN A. Les polyosides de la goyave (Psidium guajava L. ). Evolution au cours de la croissance et incidences technologiques lièes à l'obtention de purées et de jus. Fruits 1990; 45(5): 511-20.

4. LE BELLEC F, RENAUD V. Le grand livre des fruits tropicaux. Edition Orphic, 1997.

5. SCHÄFER K. Accelerared solvent extraction of lipids for determining the fatty acid composition of biological material. Anal Chim Acta 1998; 358: 69-77.

6. GALLINA TOSCHI T, BENDINI A, RICCI A, LERCKER G. Pressurized extraction of total lipids in poultry meat. Food Chem 2003; 83: 551-5.

7. TURON F, BACHAIN P, CARO Y, PINA M, GRAILLE J. A Direct Method for Regiospecific Analysis of TAG using a-MAG. Lipids 2002; 37: 817-21.

8. AFNOR. Corps gras d'origine animale et végétale- Détermination de la teneur en stérols individuels et totaux- Méthode par chromatographie en phase gazeuse. In: Corps gras, graines oléagineuses, produits dérivés - Tome 1: Corps gras et produits dérivés. Paris: AFNOR, 2000: 283-311.

9. AFNOR. NF ISO 9936. Corps gras d'origine animale et végétale- Détermination des teneurs en tocophérols et en tocotriénols- Méthode par chromatographie en phase liquide à haute performance. Paris: AFNOR, 1997; (1-10).
10. AOCS. Free fatty acids Ab 5-49. In: Official methods and recommended practices of the American Oil Chemists Society fourth edition. Champaign, Illinois, USA: AOCS Press, 1989

11. CODEX STAN. Codex Alimentarius. Rome, Italy: FAO Information division, 1999.

12. ZÖLLNER N. Dietary linolenic acid in man: an overview. Prog Lipid Res 1986; 25: $177-80$.

13. BEKAERT A, DELAGE V, ANDRIEUX J, PLAT M. Etude de la fraction lipidique des graines d'Actinidia chinensis (Planch.) Dilleniacées ou Kiwi. Revue Française des corps gras 1987; 10-11: 463-4.

14. GAYDOU EM, RAMANOELINA ARP. Valorisation des sous-produits de I'industrie du jus des fruits de grenadille: Composition en acides gras et en stérols de l'huile des graines. Fruits 1983; 38(10): 699-703.

15. MENDY F. Synergie et acides gras. XXI siècle: Une ère nouvelle pour les lipides. OCL 2005; 12: 5-15.

16. AWAD A, TOCZEK J, FINK CS. Phytosterols decrease prostaglandin release in cultured P338D1/MAB macrophages. Prostaglandins, Leukotrienes and essential Fatty Acids 2004; 70: 511-20.

17. VIVANCOS M, MOPENO $\vartheta \vartheta$. $\beta$ sitosterol modulates antioxydant enzyme response in RAW 264. 7 macrophages. Free Radic Biol Med 2005; 39: 91-97.

18. ROSSIGNOL-CASTERA A, BOSQUE F. Nouvelle Approche des Antioxydants. OCL 1994: 1: 10-5. 